\title{
Ram Sperm Motility Parameters under The Influence of Epidermal Growth Factor
}

\author{
Eliška Špaleková, ${ }^{1}$ Alexander V. Makarevich, ${ }^{2}$ and Norbert Lukáč ${ }^{1}$ \\ ${ }^{1}$ Department of Animal Physiology, Faculty of Biotechnology and Food Sciences, Slovak University of Agriculture Nitra, \\ Trieda A. Hlinku 2, 94976 Nitra, Slovakia \\ ${ }^{2}$ Institute for Farm Animal Genetics and Reproduction, Animal Production Research Centre Nitra, Hlohovecká 2, 95141 Nitra, Slovakia
}

Correspondence should be addressed to Eliška Špaleková, spalekova.eliska@gmail.com

Received 2 December 2010; Accepted 2 March 2011

Academic Editor: Cynthia L. Baldwin

Copyright @ 2011 Eliška Špaleková et al. This is an open access article distributed under the Creative Commons Attribution License, which permits unrestricted use, distribution, and reproduction in any medium, provided the original work is properly cited.

\begin{abstract}
Epidermal growth factor (EGF) is one of the important cytokines that play a role in fertility. It is known that EGF affects both male and female reproduction, but its effect on sperm parameters is not fully understood. Up to the present, the effect of EGF on ram sperm motility parameters has not been published. We analyzed motility parameters of ejaculates after 24,48 , and 72 hours from the EGF addition. EGF was added to chilled ram sperm at concentrations of $0,100,200$, and $400 \mathrm{ng} \cdot \mathrm{ml}^{-1}$. Analyses were realized using computer, assisted semen analyzer (CASA)—Hamilton Thorn motility analyzer (version 7). The effect of EGF was already visible after $30 \mathrm{~min}$ of incubation. Significant effect on ram sperm total motility and progressive movement was observed at higher EGF concentrations after $48 \mathrm{~h}$ of incubation. Our results show that EGF affects sperm motility parameters depending on concentration and time of exposure.
\end{abstract}

\section{Introduction}

Epidermal growth factor (EGF) has been shown to have a role in both male as well as female mammalian reproduction $[1,2]$. EGF has been found in rat and human seminal plasma $[3,4]$. Effects of EGF are probably exerted directly via EGF receptors which have been found in the acrosomal region of the spermatozoa [5] from various mammalian species including human, mouse, rabbit, bovine, and rat $[6,7]$. Under in vitro conditions, EGF regulates capacitation, acrosome reaction, and motility in mouse, bovine, and human spermatozoa [8-11]. In in vivo experiments the administration of EGF improved rat epididymal sperm content and motility [12]. The removal of the submandibular gland (a source of EGF production) in mature male mice results in significant loss of plasma EGF, causing a significant decrease of spermatids in the testes and mature sperm in the epididymis [13]. These observations suggest the role of EGF in the regulation of sperm functions.
However, knowledge about EGF effect on sperm characteristics is inconsistent. Thus, Naz and Kaplan [11] in human sperm showed that EGF decreased sperm penetration rate and altered sperm motility characteristics. However, other research teams reported no effect of EGF on human sperm motility $[9,14]$. This controversy may be explained by different experimental setting used by Naz and Kaplan [11], who incubated the sperm for a shorter period.

Moreover, there are no reports about EGF effects on movement characteristics of ram sperm. In our work, we focused on assessing the effect of EGF on total motility and progressive motility of ram sperm. Motility of sperm cells may be measured using both subjective and objective evaluation. Objective evaluation of sperm motility by CASA gives more accurate assessment of sperm which can better predict further fertility than visual estimation. We evaluated the dynamics of EGF action on parameters of total motility and progressive movement of ram sperm following several days of storage at cooling conditions. The assessment of ram 


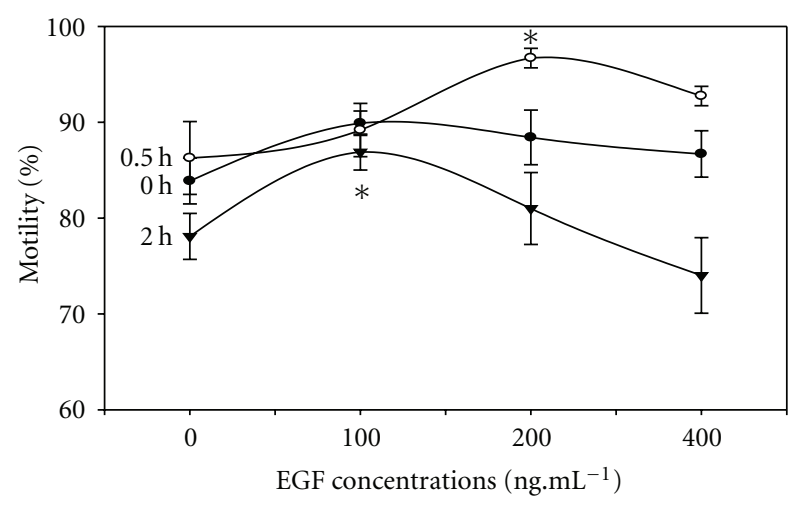

FIgUre 1: Dynamics of EGF effect on ram sperm motility. Significant difference compared to control, ${ }^{*} P<.05$.

sperm motility parameters was realized using computerassisted sperm analyzer (CASA).

\section{Experimental Procedures}

All the experiments were carried out with fresh ram spermatozoa. The semen was collected from East-Friesian (VF) and Lacaune (Lc) rams using artificial vagina. The rams were kept at a local farm under uniform nutritional conditions. Volume, concentration, and sperm activity where assessed shortly after collection. Ejaculates from all rams were pooled together to make heterospermia in order to avoid individual influence of ram and were used for the assay. Ejaculates were diluted in Triladyl (Minitüb, Tiefenbach, Germany) containing 20\% egg yolk, lactose, and 6\% glycerol. Semen was cooled at $5-7^{\circ} \mathrm{C}$, transported to the laboratory, and kept in a fridge for one week. Samples were divided into four groups, with $1 \mathrm{~mL}$ of ejaculates in each, and subsequently EGF (recombinant; Sigma-Aldrich Ltd, Bratislava, Slovakia) was added at concentrations of 100,200 , and $400 \mathrm{ng} \cdot \mathrm{mL}^{-1}$, whereas control group did not contain EGF $\left(0 \mathrm{ng} \cdot \mathrm{mL}^{-1}\right)$. We analyzed motility parameters of ejaculates after 24,48 , and 72 hours from the EGF addition. Analyses were realized using computer-assisted semen analyzer (CASA)-Hamilton Thorn motility analyzer (version 7). We analyzed, effect of various concentrations of EGF on ram sperm motility and progressive movement, as well as the dynamics of the effect of EGF after its addition for different time periods $(0,0.5$, and $2 \mathrm{~h}$ ).

Experiments have been done in three replications. The results were statistically evaluated by two-way ANOVA test and graphically processed using SigmaPlot graphic software (version 9.01 for windows).

\section{Results}

EGF affected observed parameters of sperm motility following 0.5 hours of incubation. The more expressed effect of EGF at this time point was observed at the concentration of $200 \mathrm{ng} \cdot \mathrm{mL}^{-1}$, where total motility was increased from $86.3 \%$ (control group) to $96.7 \%$. After 2 hours of incubation, the

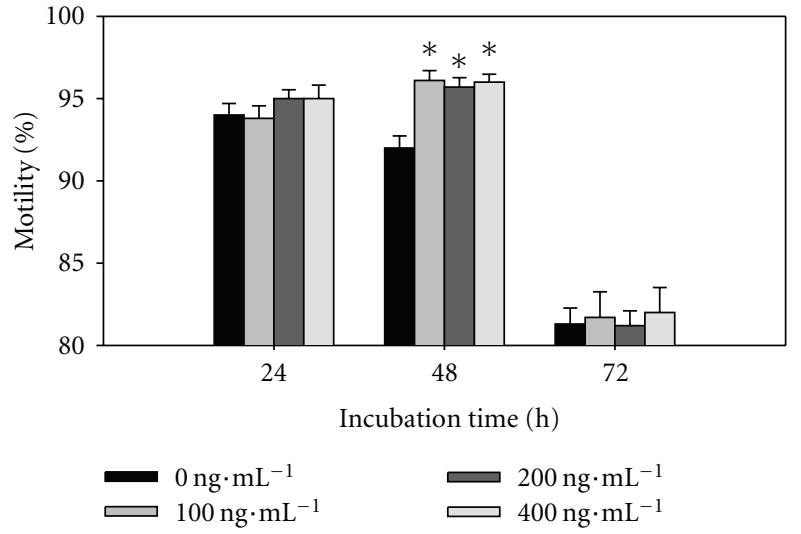

FIGURE 2: Effect of cooling storage in the presence of EGF on sperm motility. Significant difference compared to control, ${ }^{*} P<.05$.

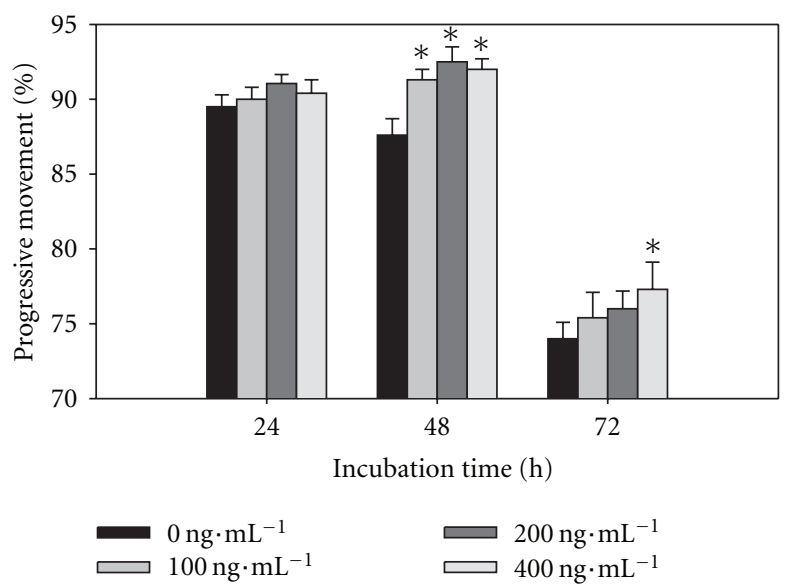

FIGURE 3: Effect of cooling storage in the presence of EGF on sperm progressive movement. Significant difference compared to control, ${ }^{*} P<.05$.

stimulating effect of EGF was visible at the concentration of $100 \mathrm{ng} \cdot \mathrm{mL}^{-1}$. Further elevation of EGF concentration above $200 \mathrm{ng} \cdot \mathrm{mL}^{-1}$ was not effective at any time interval of sperm incubation in the presence of EGF (Figure 1).

The effect of EGF on the motility of cooling-stored sperm after 24, 48, or 72 hours is shown in Figure 2. Slight but not significant increase in total motility following 24 hours was observed at concentrations of 200 and $400 \mathrm{ng} \cdot \mathrm{mL}^{-1}$. Significantly higher motility at all concentrations of EGF was observed after 48 hours of sperm storage, although sperm motility in the control group was reduced when compared to the $24 \mathrm{~h}$ interval of sperm storage. Following $72 \mathrm{~h}$ of cooling storage, total sperm motility was dramatically reduced compared to the 24 or $48 \mathrm{~h}$ interval, and no effect of EGF at all concentrations was observed (Figure 2).

No significant increase in progressive movement among all tested groups was observed following $24 \mathrm{~h}$ storage of ram sperm in the presence of EGF (Figure 3 ). Significant increase $(P<.05)$ in progressive movement at all tested concentrations of EGF in comparison to the control group 


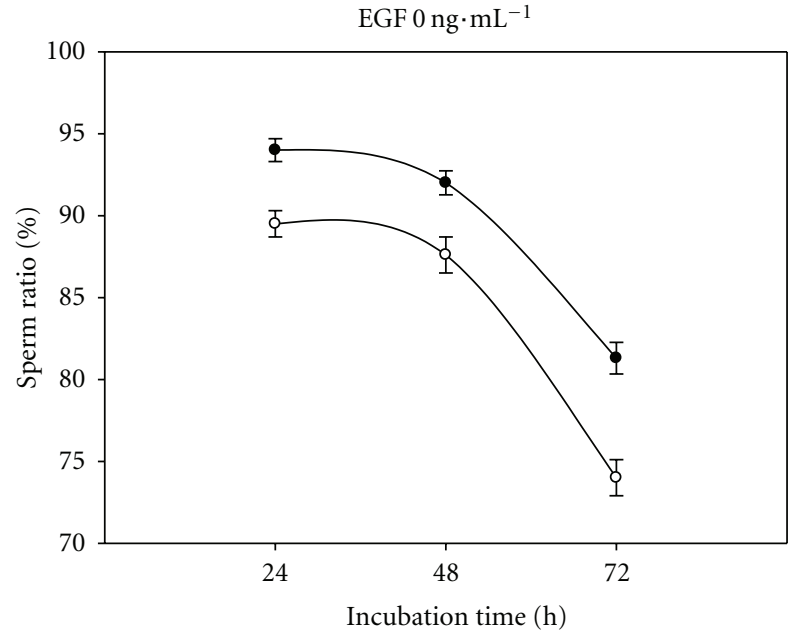

(a)

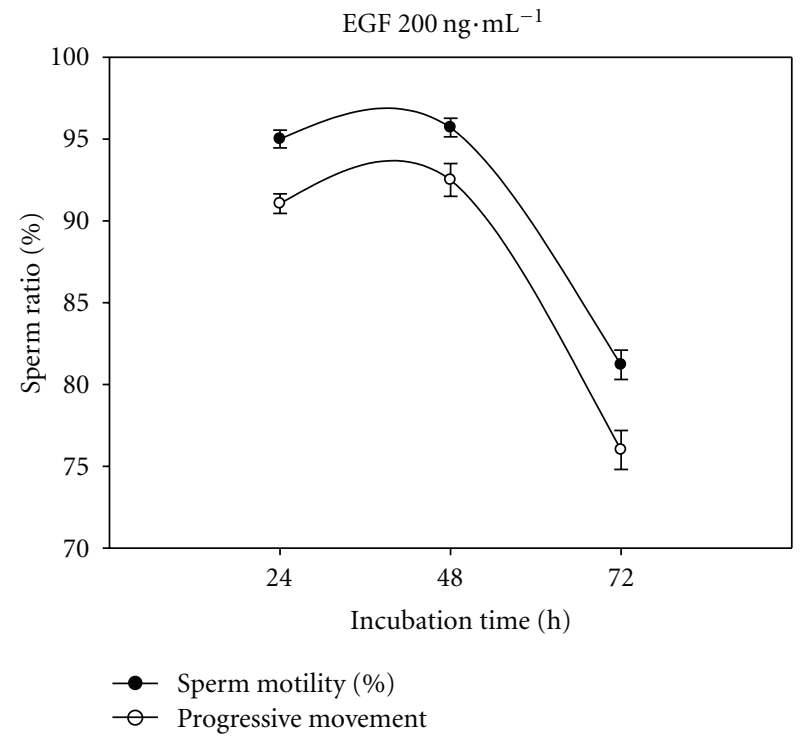

(c)

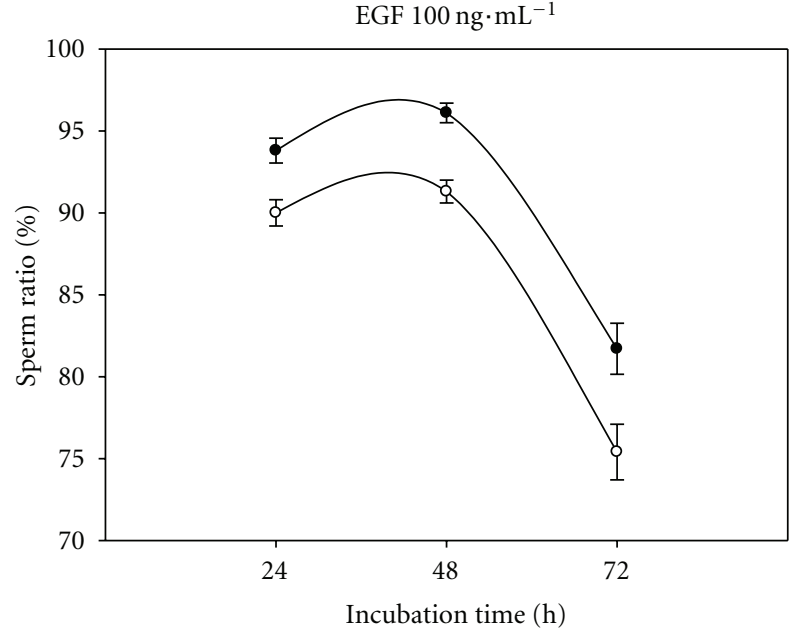

(b)

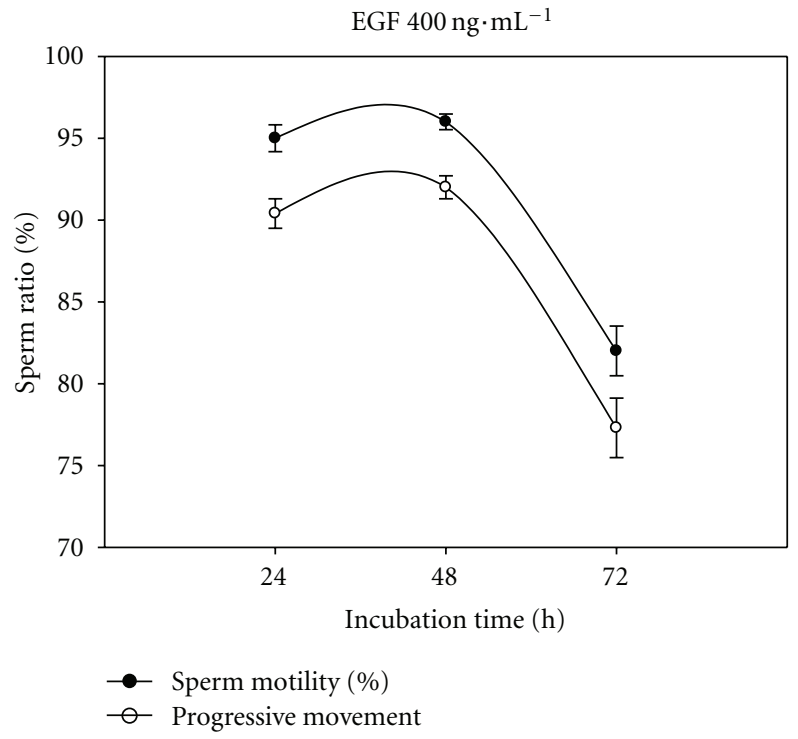

(d)

FIGURE 4: Interrelationships between total motility and progressive movements depended upon EGF concentrations and length of cooling storage.

was observed following $48 \mathrm{~h}$ storage of ram sperm. Following $72 \mathrm{~h}$ of storage, significant increase in progressive motility was observed only when EGF at the highest concentration $\left(400 \mathrm{ng} \cdot \mathrm{mL}^{-1}\right)$ was applied.

Progressive movement values were lower than total sperm motility; nevertheless, the similar pattern of curves for both the total motility and the progressive movement was visible in control group. However, such an equal character of both curves was not noted in either group with EGF. At concentrations of 200 and $400 \mathrm{ng} \cdot \mathrm{mL}^{-1}$ EGF, values of progressive movement were situated close to the percentage of total motility beginning from 48 hour of cooling storage (Figure 4).

\section{Discussion}

Effect of EGF on sperm has not been fully elucidated yet. There is a report stating that EGF given at concentrations about $100 \mathrm{ng} \cdot \mathrm{mL}^{-1}$ did not affect several parameters of spermatozoa like acrosomal status, membrane integrity, or motility patterns [7]. On the other hand, Naz and Kaplan [11] suggested that EGF, given at higher concentrations, may inhibit capacitation and/or the acrosome reaction of human sperm. Oliva-Hernández and Peréz-Gutiérrez [7] observed that endogenous EGF produced in the reproductive tract may increase the quality of boar sperm movement after acrosome reaction.

Results of our work confirm that EGF affects sperm motility parameters depending on the concentration and time of exposure to EGF. The highest effect on ram sperm motility was observed at higher EGF concentrations. The effect of EGF in our study was exhibited already after 30 min of incubation. These results are consistent with the previous study of Naz and Kaplan [11], who showed that EGF did not affect the motility of human sperm at concentrations below $100 \mathrm{ng} \cdot \mathrm{mL}^{-1}$, whilst concentrations above 
$100 \mathrm{ng} \cdot \mathrm{mL}^{-1}$ significantly affected all motility parameters, such as velocity, linearity, beat frequency, and amplitude of lateral head displacement.

The importance of sperm motility during the fertilization process has attracted considerable attention over the past decades. Several researchers have reported the relationship between fertility potential in vitro and sperm motility parameters measured with CASA $[15,16]$. Some studies [17-21] suggested that the characteristics of progressive motility of the spermatozoa were related to their fertilizing capacity and the sperm motility was dependent on mitochondrial function. When the sperm mitochondrial membrane potential increases, sperm motility parameters and fertility potential will also increase [16].

It is well known that premature capacitation occurs during the processing of semen samples, ultimately leading to a reduced fertility in comparison to fresh semen samples [22]. The high percentage of motile spermatozoa in processed semen samples in our tests may indicate that these spermatozoa have not been damaged by the process of dilution and storage. Our results indicate that EGF also affects the progressive movement, important for fertilization ability of sperm. The importance of the effect of EGF is also in the retention of motility of cooling-stored sperm for a longer period $(72 \mathrm{~h})$.

The assessment of quality (speed) of progressive motility is very important because it is an essential prognostic fertility factor, especially when the proportion of motile spermatozoa is below $40 \%$ [23]. Objective analysis of sperm motility parameters resulted in significant correlations between the value of lateral head displacement (ALH) [24], curvilinear velocity (VCL) [25-27], average path velocity (VAP) [28], linearity (LIN) [26], and the in vitro fertilization rates. In addition to VCL and VAP, sperm hyperactivation has been shown to be an important marker of fertilizing ability in the in vitro situation $[27,29-31]$.

Sperm motility is commonly believed to be one of the most important characteristics for evaluating the fertility potential of ejaculated spermatozoa. However, in bulls, no significant correlation between the percentage of motile spermatozoa evaluated by CASA and the 59-day NRR (nonreturn rate) has been found, whereas highly significant correlations were detected when CASA parameters describing the velocity of motile spermatozoa or the trajectory line of motile spermatozoa were included [32]. In earlier studies on boar, no relationship between motility parameters evaluated by CASA and fertility of boars was found [33, 34]. More recently, results of a fertility trial demonstrated a correlation between objectively measured boar sperm motility parameters and the outcomes of on-farm inseminations [35]. In the study of Hirai et al. [36], a significant difference in the percentage of motile spermatozoa between boars with high or low litter size was demonstrated.

The high percentage of motile spermatozoa in processed semen samples may indicate that these spermatozoa have not been damaged by the process of dilution and storage. It is well known that premature capacitation occurs during the processing of semen samples, ultimately leading to a reduced fertility in comparison to fresh semen samples [22].
Optimal value of sperm motility and progressive movement are important factors for successful fertilization. EGF affects sperm motility parameters depending on concentration and time of exposure to EGF. The effect of EGF addition on cooling-stored ram sperm was visible after $30 \mathrm{~min}$ of incubation, and the more expressed effect was observed at the concentration of $200 \mathrm{ng} \cdot \mathrm{mL}^{-1}$. The higher concentration of EGF $\left(100,200\right.$, and $\left.400 \mathrm{ng} \cdot \mathrm{mL}^{-1}\right)$ significantly helped in the retention of motility and progressive movement of coolingstored sperm for a longer period ( $48 \mathrm{~h})$.

\section{Acknowledgment}

This work was supported by the Slovak Research and Development Agency under the Contract no. APVV-0514-07.

\section{References}

[1] E. D. Adamson, "EGF receptor activities in mammalian development," Molecular Reproduction and Development, vol. 27, no. 1, pp. 16-22, 1990.

[2] K. Ahmad and R. K. Naz, "Role of epidermal growth factor in reproduction," Assist Reprod Tech Androl, vol. 4, pp. 85-92, 1993.

[3] Y. Hirata, M. Uchihashi, M. Hazama, and T. Fujita, "Epidermal growth factor in human seminal plasma," Hormone and Metabolic Research, vol. 19, no. 1, pp. 35-37, 1987.

[4] H. Kishi, T. Ishibe, T. Usui, and Y. Miyachi, "Epidermal growth factor (EGF) in seminal plasma and prostatic gland: a radioreceptor assay," Archives of Andrology, vol. 20, no. 3, pp. 243-249, 1988.

[5] R. K. Naz and K. Ahmad, "Presence of expression products of c-erbB-1 and c-erbB-2/HER2 genes on mammalian sperm cell, and effects of their regulation on fertilization," Journal of Reproductive Immunology, vol. 21, no. 3, pp. 223-239, 1992.

[6] R. K. Naz and B. S. Minhas, "Enhancement of sperm function for treatment of male infertility," Journal of Andrology, vol. 16, no. 5, pp. 384-388, 1995.

[7] J. Oliva-Hernández and J. F. Pérez-Gutiérrez, "Localization of the epidermal growth factor (EGF) in the epididymis and accessory genital glands of the boar and functional effects on spermatozoa," Theriogenology, vol. 70, no. 7, pp. 1159-1169, 2008.

[8] Y. Lax, S. Rubinstein, and H. Breitbart, "Epidermal growth factor induces acrosomal exocytosis in bovine sperm," FEBS Letters, vol. 339, no. 3, pp. 234-238, 1994.

[9] S. Furuya, Y. Endo, M. Oba, S. Suzuki, and S. Nozawa, "Effect of epidermal growth factor on human sperm capacitation," Fertility and Sterility, vol. 60, no. 5, pp. 905-910, 1993.

[10] T. Murase and E. R. Roldan, "Epidermal growth factor stimulates hydrolysis of phosphatidylinositol 4,5-bisphosphate, generation of diacylglycerol and exocytosis in mouse spermatozoa," FEBS Letters, vol. 360, no. 3, pp. 242-246, 1995.

[11] R. K. Naz and P. Kaplan, "Effects of epidermal growth factor on human sperm cell function," Journal of Andrology, vol. 14, no. 4, pp. 240-247, 1993.

[12] D. Cheng, X. M. Zheng, S. W. Li, Z. W. Yang, and L. Q. $\mathrm{Hu}$, "Effects of epidermal growth factor on sperm content and motility of rats with surgically induced varicoceles," Asian Journal of Andrology, vol. 8, no. 6, pp. 713-717, 2006. 
[13] O. Tsutsumi, H. Kurachi, and T. Oka, "A physiological role of epidermal growth factor in male reproductive function," Science, vol. 233, no. 4767, pp. 975-977, 1986.

[14] K. Zitta, M. Albrecht, S. Weidinger, A. Mayerhofer, and F. Köhn, "Protease activated receptor 2 and epidermal growth factor receptor are involved in the regulation of human sperm motility," Asian Journal of Andrology, vol. 9, no. 5, pp. 690-696, 2007.

[15] K. A. Ginsburg, A. G. Sacco, J. W. Ager, and K. S. Moghissi, "Variation of movement characteristics with washing and capacitation of spermatozoa. II. Multivariate statistical analysis and prediction of sperm penetrating ability," Fertility and Sterility, vol. 53, no. 4, pp. 704-708, 1990.

[16] T. Kasai, K. Ogawa, K. Mizuno et al., "Relationship between sperm mitochondrial membrane potential, sperm motility, and fertility potential," Asian Journal of Andrology, vol. 4, no. 2, pp. 97-103, 2002.

[17] R. O. Davis, J. W. Overstreet, R. H. Asch, T. Ord, and S. J. Silber, "Movement characteristics of human epididymal sperm used for fertilization of human oocytes in vitro," Fertility and Sterility, vol. 56, no. 6, pp. 1128-1135, 1991.

[18] P. Terriou, C. Giorgetti, P. Auquier et al., "Comparison of optical analysis and computerized analysis of sperm movement in a program of 316 in vitro fertilizations," Contraception Fertilite Sexualite, vol. 22, no. 6, pp. 418-422, 1994.

[19] L. Larsen, T. Scheike, T. K. Jensen et al., "Computer-assisted semen analysis parameters as predictors for fertility of men from the general population," Human Reproduction, vol. 15, no. 7, pp. 1562-1567, 2000.

[20] Y. Hirano, H. Shibahara, H. Obara et al., "Relationships between sperm motility characteristics assessed by the computer-aided sperm analysis (CASA) and fertilization rates in vitro," Journal of Assisted Reproduction and Genetics, vol. 18, no. 4, pp. 213-218, 2001.

[21] J. P. T. Rhemrev, J. W. Lens, J. McDonnell, J. Schoemaker, and J. P. W. Vermeiden, "The postwash total progressively motile sperm cell count is a reliable predictor of total fertilization failure during in vitro fertilization treatment," Fertility and Sterility, vol. 76, no. 5, pp. 884-891, 2001.

[22] N. Cormier, M. A. Sirard, and J. L. Bailey, "Premature capacitation of bovine spermatozoa is initiated by cryopreservation," Journal of Andrology, vol. 18, no. 4, pp. 461-468, 1997.

[23] R. Eliasson, "Semen analysis with regard to sperm number, sperm morphology and functional aspects," Asian Journal of Andrology, vol. 12, no. 1, pp. 26-32, 2010.

[24] C. Jeulin, D. Feneux, C. Serres et al., "Sperm factors related to failure of human in vitro fertilization," Journal of Reproduction and Fertility, vol. 76, no. 2, pp. 735-744, 1986.

[25] S. Y. W. Chan, C. Wang, S. T. H. Chan et al., "Predictive value of sperm morphology and movement characteristics in the outcome of in vitro fertilization of human oocytes," Journal of In Vitro Fertilization and Embryo Transfer, vol. 6, no. 3, pp. 142-148, 1989.

[26] D. Vantman, S. M. Bands, G. Koukoulis, L. Dennison, and R. J. Sherins, "Assessment of sperm motion characteristics from fertile and infertile men using a fully automated computerassisted semen analyzer," Fertility and Sterility, vol. 51, no. 1, pp. 156-161, 1989.

[27] C. De Geyter, M. De Geyter, B. Koppers, and E. Nieschlag, "Diagnostic accuracy of computer-assisted sperm motion analysis," Human Reproduction, vol. 13, no. 9, pp. 2512-2520, 1998.
[28] D. Y. Liu, G. N. Clarke, and H. W. G. Baker, "Relationship between sperm motility assessed with the Hamilton-Thorn motility analyzer and fertilization rates in vitro," Journal of Andrology, vol. 12, no. 4, pp. 231-239, 1991.

[29] P. J. Chan, S. G. Prough, I. Henig, and D. R. Tredway, "Predictive value of sperm hyperactivation measurements based on the dilution effect method in clinical in vitro fertilization," International Journal of Fertility, vol. 37, no. 6, pp. 373-377, 1992.

[30] C. Wang, G. S. Lee, A. Leung, E. S. Surrey, and S. Y. W. Chan, "Human sperm hyperactivation and acrosome reaction and their relationships to human in vitro fertilization," Fertility and Sterility, vol. 59, no. 6, pp. 1221-1227, 1993.

[31] J. F. Guérin, P. Gallot-Lavallée, J. Lornage et al., "In vitro fertilization failures related to a sperm hyperactivation defect: indication for microinjection?" Contraception Fertilite Sexualite, vol. 23, no. 7-8, pp. 466-467, 1995.

[32] P. B. Farrell, G. A. Presicce, C. Brockett, and R. H. Foote, "Quantification of bull sperm characteristics measured by computer-assisted sperm analysis (CASA) and the relationship to fertility," Theriogenology, vol. 49, no. 4, pp. 871-879, 1998.

[33] R. Aumüller and H. Willeke, "Computer controlled analysis of boar semen with the "Cellsoft" system," in Proceedings of the 11th International Congress on Animal Reproduction and Artificial Insemination, vol. 227, Dublin, Ireland, 1988.

[34] D. Rath, S. Armbrecht, P. Schaap, and K. F. Weitze, "Experiences with a computerized videomicrographic system for sperm analysis," in Proceedings of the 11th International Congress on Animal Reproduction and Artificial Insemination, vol. 3, 288, Dublin, Ireland, 1988.

[35] C. Holt, W. V. Holt, H. D. M. Moore, H. C. B. Reed, and R. M. Curnock, "Objectively measured boar sperm motility parameters correlate with the outcomes of on-farm inseminations: results of two fertility trials," Journal of Andrology, vol. 18, no. 3, pp. 312-323, 1997.

[36] M. Hirai, A. Boersma, A. Hoeflich et al., "Objectively measured sperm motility and sperm head morphometry in boars (Sus scrofa): relation to fertility and seminal plasma growth factors," Journal of Andrology, vol. 22, no. 1, pp. 104-110, 2001. 

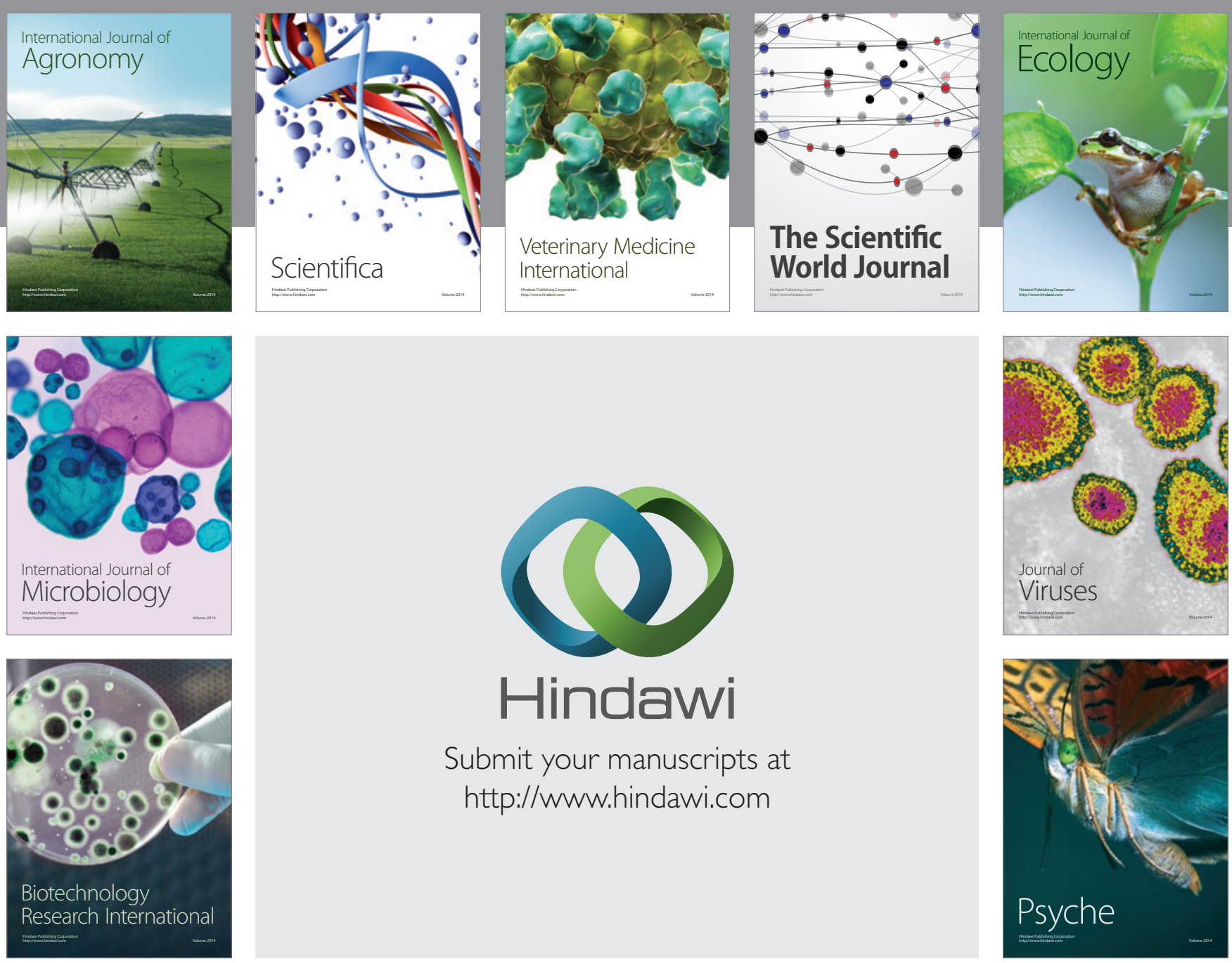

Submit your manuscripts at

http://www.hindawi.com
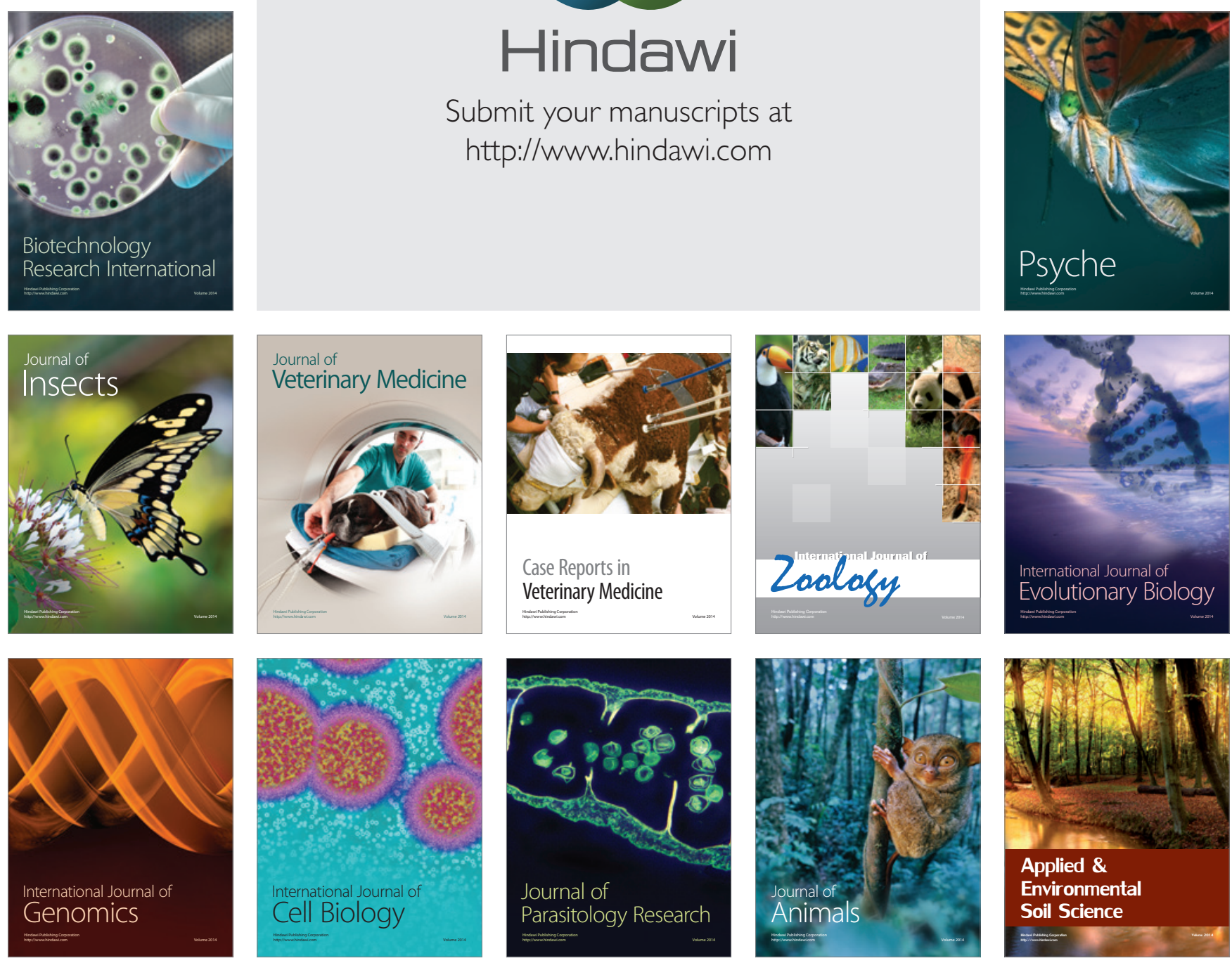